\title{
Incentives for Blood Donation: A Discrete Choice Experiment to Analyze Extrinsic Motivation
}

\author{
Andrew Sadler ${ }^{a}$ Ling Shi ${ }^{b}$ Susanne Bethge ${ }^{a}$ Axel Mühlbacher ${ }^{a}$ \\ ${ }^{a}$ Gesundheitsökonomie und Medizinmanagement, Hochschule Neubrandenburg, Neubrandenburg, Germany; \\ ${ }^{b}$ Department of Nursing, University of Massachusetts Boston, Boston, MA, USA
}

\section{Keywords}

Blood donation - Incentives - Discrete choice experiment . DCE · Random parameter logit model

\section{Summary}

Background: Demographic trends affect size and age structure of populations. One of the consequences will be an increasing need for blood products to treat age-related diseases. Donation services rely on voluntariness and charitable motivation. It might be questioned whether there will be sufficient blood supply with voluntary donation. The present study focused on elicitation of preferences for incentives and aimed to contribute to the discussion on how to increase donation rates. Methods: $A$ self-administered discrete choice experiment (DCE) was applied. Respondents were repeatedly asked to choose between hypothetical blood donation centers. In case of reluctance to receiving incentives a none-option was included. Random parameter logit (RPL) and latent class models (LCM) were used for analysis. Results: The study sample included 416 college students from the US and Germany. Choice decisions were significantly influenced by the characteristics of the donation center in the DCE. Incentives most preferred were monetary compensation, paid leave, and blood screening test. LCM identified subgroups with preference heterogeneity. Small subgroups indicated moderate to strong aversion to incentives. Conclusion: The majority of the sample positively responded to incentives and indicated a willingness to accept incentives. In face of future challenges, the judicious use and appropriate utilization of incentives might be an option to motivate potential donors and should be open to discussion.

(c) 2018 S. Karger GmbH, Freiburg

\section{Introduction}

Background and Policy Context

Aging of the population is a matter of fact in most industrialized countries. Demographic trends affect size and age structure of the populations. Consequences will be the growth of old age groups thereby increasing the patient population. even though technical improvements, enhanced blood management and personalized medicine might lead to a more efficient use of blood and transfusion rates, the demand for blood products is expected to increase substantially in the next years [1-5]. In contrast, in recent years the number of blood donations remained unchanged or even declined [7]. This is due to the fact, that only small shares of populations donate blood on a regular basis [9-12]. In the US only $4.5 \%$ [11] and in Germany only $4.3 \%$ of the eligible population donates blood [5].

Motivating people to donate blood appears to be a difficult task [13]. This poses the question whether and how blood supply can be ensured in the future. The question was often addressed, and debating of a promising solution has been started - the provision of incentives $[14,15]$. Individuals might simply find it not worthwhile to dedicate time to donation when private benefits fall short of the opportunity costs. This implies that policies offering explicit incentives might play a role in encouraging participation in activities that are, in most countries, based on voluntary and unpaid contributions [16]. Then the call for altruistic donations might not be heard by everyone, and recruitment campaigns might not be sufficient enough even with an existing willingness to donate in populations.

\section{Ethical Controversy and Current Debate}

Compensating donors for blood donation has been controversial and emotive for decades $[15,19-22]$. One major concern is that incentives detrimentally affect blood safety by attracting at-risk donors who may conceal risk behaviors in order to obtain incentives and that incentives may discourage regular donors who primarily

\section{KARGER}

(c) 2018 S. Karger GmbH, Freiburg

Fax +497614520714 
Table 1. Attributes and levels used in the DCE

\begin{tabular}{lll}
\hline Attributes & Levels & Description \\
\hline Paid leave & $0.5 / 1.0 / 1.5$ day(s) & donor earns paid leave. \\
Money for donor & $10 / 20 / 30$ EUR (USD) & donor receives cash payment. \\
Blood screening & standard / comprehensive / plus & donor receives a screening test \\
Money for charity & $10 / 20 / 30$ EUR (USD) & money is given to charity. \\
Privileged receiver & unknown / donor / immediate relative & receiver of donated blood. \\
Small gift & gift card / badge / certificate & donor receives a small gift. \\
Travel time & $30 / 20 / 10$ min & travel time to donation center. \\
\hline *EUR (Germany), USD (US). & \\
\hline
\end{tabular}

donate for altruistic reasons [20, 23-27]. Standard economic theory predicts that offering extrinsic incentives increases the provision of pro-social activities by adding value to the intrinsic motivation. Alternative frameworks, however, predict that offering rewards can backfire because they might crowd out intrinsic motives [16]. Extrinsic incentives such as money rewards are said to be negatively correlated with intrinsic motives such as the desire to help [18, 23, 28-31]. On the other hand, studies showed that blood donors did not seem to be averse to rewards for pro-social activities and donation behavior did not seem to be affected when offering incentives $[22,32]$.

The objective of the study was to evaluate whether respondents are generally willing to accept incentives such as cash payment in exchange for blood donation, thus contributing to the current debate. A better understanding of preferences of potential donors for incentives may help to encourage blood donation. Furthermore, the study was conducted in the US and Germany in order to compare preferences across countries.

\section{Material and Methods}

\section{Discrete Choice Experiment}

An online Discrete Choice Experiment (DCE) was conducted to quantify preferences for incentives in exchange for blood donation. Respondents were repeatedly asked to choose between two hypothetical (unlabeled) blood donation centers varying in seven characteristics (also called attributes). In case of reluctance to receiving incentives a none-option (opt-out) was included in the experiment. Attributes were primarily identified from a literature review and a pilot study. Eventually seven attributes were identified as important for regular and potential blood donors. Final attributes (table 1) represented extrinsic (economic) incentives, e.g. cash payment, and intrinsic incentives like pro-social motivators, e. g. charitable donation. The study was reviewed and approved by the Institutional Review Board (IRB) at University of Massachusetts Boston.

\section{Study and Survey Design}

Stated preference methods such as the DCE have been commonly used in health care and health economics [39-42]. The DCE is an (multi)attributebased survey method for analyzing latent preference structures and measuring utilities in order to gain information on assessment and forecast of demand and acceptance of healthcare products or services. In a DCE, respondents are presented with samples of (hypothetical) scenarios drawn a priori from all possible choice sets according to statistical design principles. Most commonly, each respondent faces a series of choice questions. Scenarios generally consist of two or more alternatives each described by various attributes. Respondents are asked to choose the preferred alternative. It is assumed that individuals derive utility from the underlying attributes of the alternative under valuation
Table 2. Descriptive data of US and German sample

\begin{tabular}{|c|c|c|}
\hline & $\begin{array}{l}\text { US } \\
(\mathrm{N}=103)\end{array}$ & $\begin{array}{l}\text { Germany } \\
(\mathrm{N}=313)\end{array}$ \\
\hline Age (mean and standard deviation) $)^{* * *}$ & $25.2 \pm 6.5$ & $22.9 \pm 2.8$ \\
\hline \multicolumn{3}{|l|}{ Age groups $s^{* *}$} \\
\hline $18-20$ years & $29(28 \%)$ & $75(24 \%)$ \\
\hline $21-25$ years & $37(36 \%)$ & $184(59 \%)$ \\
\hline $26-30$ years & $20(19 \%)$ & $50(16 \%)$ \\
\hline$>30$ years & $17(17 \%)$ & $4(1 \%)$ \\
\hline \multicolumn{3}{|l|}{$\operatorname{Sex}^{* * *}$} \\
\hline Female & $81(79 \%)$ & $171(55 \%)$ \\
\hline Male & $20(19 \%)$ & $139(44 \%)$ \\
\hline \multicolumn{3}{|l|}{ Household income ${ }^{* * *}$} \\
\hline Less than USD 1,000 (EUR 750) & $28(27 \%)$ & $117(37 \%)$ \\
\hline USD 1,000-2,000 (EUR 750-1,499) & $29(28 \%)$ & $123(40 \%)$ \\
\hline More than USD 2,000 (EUR 1,499) & $18(17 \%)$ & $36(11 \%)$ \\
\hline \multicolumn{3}{|l|}{ Status as blood donor ${ }^{* * *}$} \\
\hline Regular donor & $21(20 \%)$ & $100(32 \%)$ \\
\hline Donor, but not in recent 2 years & $30(29 \%)$ & $57(18 \%)$ \\
\hline Never donated & $49(48 \%)$ & $151(48 \%)$ \\
\hline \multicolumn{3}{|l|}{ Eligible to donate } \\
\hline Yes & $50(49 \%)$ & $157(50 \%)$ \\
\hline No & $20(19 \%)$ & $61(20 \%)$ \\
\hline Don't know & $31(30 \%)$ & $92(29 \%)$ \\
\hline
\end{tabular}

Percentages in categories may not add up to 100 due to missing answers. ${ }^{* *} \mathrm{p}<0.05$.

${ }^{* * *} \mathrm{p}<0.01$ (chi square, t-test statistic).

(rather than the alternative per se) and that preferences are revealed through choice decisions [43]. Choice decisions are driven by trading between attributes (e.g. incentives and costs, or effects and side effects). The goal is to analyze trade-offs respondents are willing to make between attributes [44]. Results are referred to as importance weights or preference weights of attributes and levels and can be used to calculate willingness-to-pay [45]. Estimation is applied by discrete-choice models (e.g. random parameter logit (RPL) or latent class (LC) models) which allow modeling of repeated choices by the same individual [46].

\section{Experimental Design}

The experimental design defines the experimental stimuli (choice scenarios) used to elicit choices or judgments necessary to identify preference relations. By means of the experimental design, problems of confounding and correlation can be avoided [46]. The seven attributes used in the study resulted in a full 


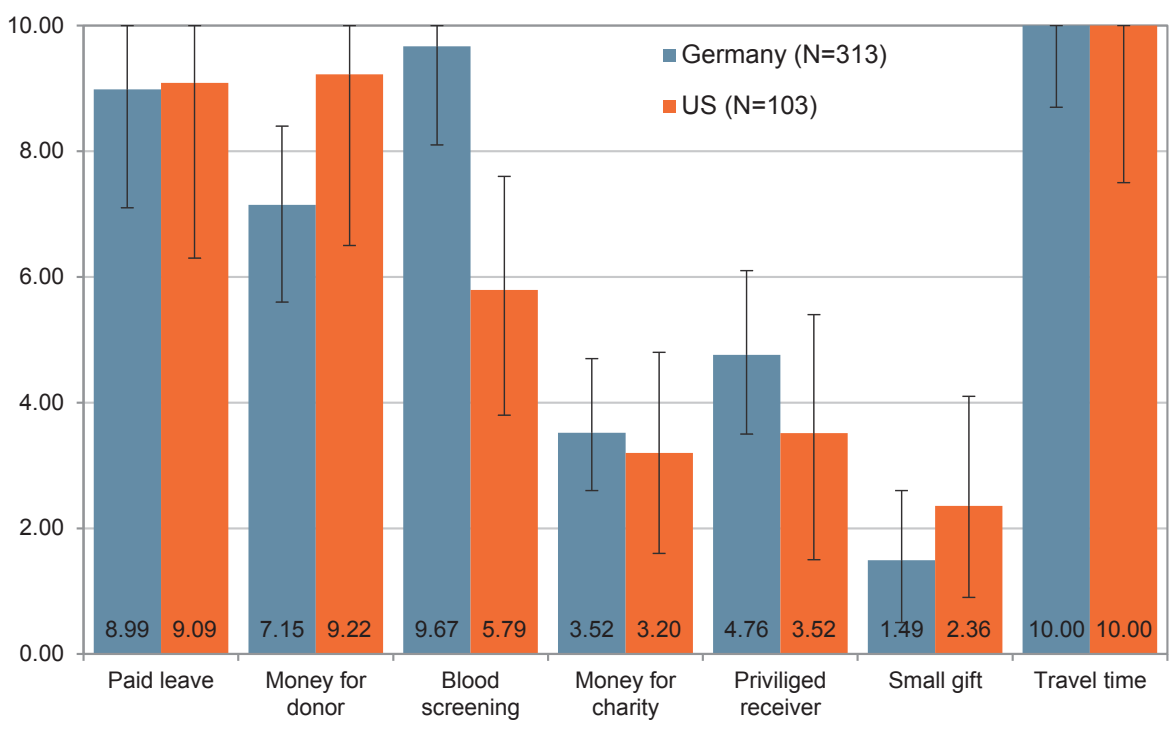

Fig. 1. Relative attribute importance (RPL model, $95 \%$ confidence interval).

factorial design of 2,187 blood donation centers. To pair the alternatives in order to obtain a feasible number of choice scenarios (here 15 sets per respondent), a fractional factorial experimental design was generated using Ngene software [47]. In the DCE, respondents stated their choice between 15 pairs of blood donation centers and a no-choice option. The dependent variable in the regression was respondent's preferred choice, and the explanatory variables were the attribute levels. Effects coding was used to allow estimation of a parameter for each attribute level [48].

\section{Recruitment}

The online-survey was conducted in 2014. Respondents were US-American and German students. Students were contacted via university mailing lists. A non-personally addressed e-mail was sent to students, inviting them to participate in the blood donation survey via the internet. The e-mail contained instructions on how to access the self-administered questionnaire. A reminder email was sent twice to the universities.

\section{Statistical Analysis}

Analysis was carried out on the basis of random utility theory [41]. Here, utility is assumed to be linear and additive and specified as:

$\mathrm{U}_{\mathrm{ik}}=\beta_{0}+\beta_{1}$ Paid leave $+\beta_{2}$ Money for donor $+\beta_{3}$ Blood screening $+\beta_{4}$ Charity $+\beta_{5}$ Privileged receiver $+\beta_{6}$ Small gift $+\beta_{7}$ Travel time $+\varepsilon_{\mathrm{ik}}$

where $U_{i k}$ is the utility that a respondent $i$ assigns to alternative $k, \beta_{0}$ is the constant which reflects the preference for selecting none of the given alternatives, $\beta_{1}$ to $\beta_{7}$ are the coefficients of the variables for respondent i representing that respondent's tastes, and $\varepsilon_{\mathrm{ik}}$ represents an error term.

Data was analyzed using a RPL and LC models. The RPL model was estimated in Stata 13.0 using mixlogit command [49]. For the LC model the lclogit and post-estimation command lclogitml were used [50]. The main objective was to estimate preference weights for attributes and attribute levels used in the experiment that are consistent with the observed pattern of choices by respondents. Furthermore, identification of subgroups was of interest. It was examined whether preferences varied within the sample population. A RPL model (also called mixed logit model) was used for estimation. The RPL model controls for the panel structure of the data and accounts for preference heterogeneity. It is assumed that the form of the function is common across individuals within the study sample but parameters vary across individuals. The model identifies attributes for which there is a significant preference variation, but does not explain why this variation exists [51]. RPL models incorporate potential estimation bias from unobserved taste heterogeneity among respondents by estimating a taste distribution for each parameter and allowing the parameters asso- ciated with the observed variables to vary randomly across individuals. Coefficients vary over respondents in the sample rather than being fixed $[43,45$, 52]. A LC model can be applied when it is believed that the sample population consists of different segments that are homogeneous in preferences. LC models express potential preference heterogeneity and fit the best possible model with a pre-determined number of classes. Coefficients are estimated for each class. LC models assume that a sample consists of a certain number of latent segments (classes) with heterogeneous preferences across segments and homogeneous preferences within segments. Where the RPL model only indicates taste variations in an overall sample, the LC model groups respondents with heterogeneous preferences into a specified number of classes. Segments are not directly observable and therefore represented by latent classes [53]. RPL and LC models have been previously used to analyze discrete choice data in healthcare $[40,51$, $54,55]$.

\section{Results}

\section{Respondents' Characteristics}

Overall, $\mathrm{N}=416$ respondents were included in the data analysis. As shown in table 2, a total of 103 US American respondents and 313 German individuals completed the survey. Statistically significant differences between samples included age, sex, and income. German respondents were younger on average. Both samples had fewer males. In the US sample, only $19 \%$ of the respondents were male, whereas $44 \%$ of the German respondents were male.

\section{RPL Model}

The results of the RPL model are reported in table 3. Statistical significance indicates whether or not a level influenced choice decisions of respondents. The coefficients can be interpreted as the relative strength or preference weight for each attribute level. Higher values are associated with higher preferences.

Analysis of the US model showed that a 10 -min travel time (Coef.: 0.85; $\mathrm{p}<0.01$ ) was most desirable followed by USD 30 money reward (Coef.: 0.75; $\mathrm{p}<0.05$ ) and 1.5 days paid leave (Coef.: $0.68 ; \mathrm{p}<0.01)$. In the German model, the most popular incentive also was a 10 -min travel time (Coef.: $0.65 ; \mathrm{p}<0.01$ ) followed by 1.5 
Table 3. Results from the random parameter model

\begin{tabular}{|c|c|c|c|c|c|c|c|c|c|c|c|c|}
\hline & \multicolumn{12}{|c|}{ Attribute / level } \\
\hline & \multicolumn{6}{|c|}{ US $(N=103)$} & \multicolumn{6}{|c|}{ Germany $(\mathrm{N}=313)$} \\
\hline & \multicolumn{2}{|l|}{$\mathrm{b}$} & \multirow[t]{2}{*}{ SE } & \multicolumn{2}{|l|}{$\mathrm{b}(\mathrm{SD})$} & \multirow[t]{2}{*}{$\mathrm{SE}(\mathrm{SD})$} & \multicolumn{2}{|l|}{$\mathrm{b}$} & \multirow[t]{2}{*}{ SE } & \multicolumn{2}{|l|}{$\mathrm{b}(\mathrm{SD})$} & \multirow[t]{2}{*}{ SE (SD) } \\
\hline Paid leave & & & & & & & & & & & & \\
\hline 0.5 day & -0.86 & $* * *$ & 0.12 & 0.81 & $* * *$ & 0.11 & -0.63 & $* * *$ & 0.06 & 0.80 & $* * *$ & 0.07 \\
\hline 1.0 day & 0.18 & $* *$ & 0.08 & -0.08 & n.s. & 0.12 & 0.01 & n.s. & 0.04 & 0.02 & n.s. & 0.07 \\
\hline 1.5 days & 0.68 & $* * *$ & 0.11 & -0.72 & $* * *$ & 0.16 & 0.62 & $* * *$ & 0.06 & -0.81 & $* * *$ & 0.10 \\
\hline \multicolumn{13}{|l|}{ Money for donor } \\
\hline USD/EUR 10 & -0.82 & $* * *$ & 0.11 & 0.62 & $* * *$ & 0.11 & -0.48 & $* * *$ & 0.05 & -0.45 & $* * *$ & 0.07 \\
\hline USD/EUR 20 & 0.07 & n.s. & 0.08 & -0.02 & n.s. & 0.09 & -0.04 & n.s. & 0.04 & -0.05 & n.s. & 0.07 \\
\hline USD/EUR 30 & 0.75 & $* * *$ & 0.11 & -0.60 & $* * *$ & 0.15 & 0.52 & $* * *$ & 0.05 & 0.50 & $* * *$ & 0.10 \\
\hline \multicolumn{13}{|l|}{ Blood screening } \\
\hline Standard & -0.55 & $* * *$ & 0.09 & 0.29 & $* * *$ & 0.09 & -0.74 & $* * *$ & 0.06 & 0.51 & $* * *$ & 0.06 \\
\hline Comprehensive & 0.12 & n.s. & 0.08 & -0.00 & n.s. & 0.10 & 0.14 & $* * *$ & 0.04 & 0.03 & n.s. & 0.06 \\
\hline Comprehensive plus & 0.43 & $* * *$ & 0.09 & -0.28 & * & 0.15 & 0.60 & $* * *$ & 0.05 & -0.54 & $* * *$ & 0.09 \\
\hline \multicolumn{13}{|l|}{ Money for charity } \\
\hline USD/EUR 10 & -0.31 & $* * *$ & 0.08 & -0.30 & $* * *$ & 0.09 & -0.32 & $* * *$ & 0.04 & 0.21 & $* * *$ & 0.08 \\
\hline USD/EUR 20 & 0.07 & n.s. & 0.08 & -0.17 & * & 0.10 & 0.16 & $* * *$ & 0.04 & -0.07 & n.s. & 0.06 \\
\hline USD/EUR 30 & 0.24 & $* * *$ & 0.09 & 0.48 & $* * *$ & 0.14 & 0.17 & $* * *$ & 0.05 & -0.15 & n.s. & 0.10 \\
\hline \multicolumn{13}{|l|}{ Privileged receiver } \\
\hline Unknown & -0.33 & $* * *$ & 0.10 & 0.64 & $* * *$ & 0.10 & -0.18 & $* * *$ & 0.06 & 0.91 & $* * *$ & 0.07 \\
\hline Donor & 0.06 & n.s. & 0.08 & 0.12 & n.s. & 0.12 & -0.24 & $* * *$ & 0.04 & -0.22 & $* * *$ & 0.07 \\
\hline Immediate relative & 0.27 & $* * *$ & 0.10 & -0.77 & $* * *$ & 0.17 & 0.42 & $* * *$ & 0.06 & -0.69 & $* * *$ & 0.10 \\
\hline \multicolumn{13}{|l|}{ Small gift } \\
\hline Gift card & -0.11 & n.s. & 0.08 & 0.28 & $* *$ & 0.12 & 0.00 & n.s. & 0.04 & -0.10 & * & 0.06 \\
\hline Badge & -0.14 & * & 0.08 & -0.34 & $* * *$ & 0.10 & -0.11 & ** & 0.04 & 0.09 & n.s. & 0.06 \\
\hline Certificate & 0.26 & $* * *$ & 0.09 & 0.06 & n.s. & 0.15 & 0.10 & $* *$ & 0.05 & 0.01 & n.s. & 0.08 \\
\hline \multicolumn{13}{|l|}{ Travel time } \\
\hline $30 \mathrm{~min}$ & -0.85 & $* * *$ & 0.12 & 0.95 & $* * *$ & 0.13 & -0.74 & $* * *$ & 0.05 & 0.20 & $* *$ & 0.10 \\
\hline $20 \mathrm{~min}$ & -0.00 & n.s. & 0.08 & -0.15 & n.s. & 0.09 & 0.09 & * & 0.04 & 0.09 & n.s. & 0.08 \\
\hline $10 \mathrm{~min}$ & 0.85 & $* * *$ & 0.12 & -0.80 & $* * *$ & 0.16 & 0.65 & $* * *$ & 0.05 & -0.29 & $* * *$ & 0.11 \\
\hline No-choice & -6.93 & $* * *$ & 1.13 & 4.20 & $* * *$ & 0.74 & -5.21 & $* * *$ & 0.45 & 3.25 & $* * *$ & 0.31 \\
\hline LL (model) & \multicolumn{6}{|c|}{-703.82} & \multicolumn{6}{|c|}{$-2,230.22$} \\
\hline AIC & \multicolumn{6}{|c|}{$1,467.63$} & \multicolumn{6}{|c|}{$4,520.44$} \\
\hline $\mathrm{BIC}$ & \multicolumn{6}{|c|}{$1,654.18$} & \multicolumn{6}{|c|}{$4,740.33$} \\
\hline Pseudo $\mathrm{R}^{2}$ & \multicolumn{6}{|c|}{0.4817} & 0.4595 & & & & & \\
\hline $\begin{array}{l}\mathrm{b}=\text { Coefficient; } \mathrm{SE}=\operatorname{stan} \\
{ }^{* *} \mathrm{p}<0.01 \\
{ }^{* *} \mathrm{p}<0.05 . \\
{ }^{*} \mathrm{p}<0.1\end{array}$ & error; S & $=$ sta & dard d & riation. & & & & & & & & \\
\hline
\end{tabular}

days paid leave (Coef.: 0.62; $\mathrm{p}<0.05$ ) and comprehensive blood screening test (Coef.: 0.62; $\mathrm{p}<0.01$ ). Parameter of the no-choice option was estimated significantly with a negative sign in both samples indicating a higher preference for one of the blood donation centers. Respondents preferred to choose one of the centers instead of the no-choice option. Significant taste heterogeneity was observed for various attributes, indicating considerable variation of preferences for incentives across respondents.

Figure 1 illustrates the relative overall importance of all attributes included in the study. Relative importance was estimated by calculating the rescaled range between the parameters for the high- est and lowest level of an attribute [56]. The most important attributes for German respondents were travel time (10.00), blood screening (9.67), paid leave (8.99), and money for donor (7.15). Less important attributes were privileged receiver (4.76) and money for charity (3.52). The least important attribute was small gift (1.49).

For the US respondents travel time (10.00) was considered most important followed by money for donor (9.22), paid leave (9.09), and blood screening test (5.79). The least important attributes were privileged receiver (3.52), money for charity (3.20) and small gift (2.36). 
Table 4. Estimates of LC model

\begin{tabular}{|c|c|c|c|c|c|c|c|c|c|c|c|c|}
\hline & \multicolumn{12}{|c|}{ Attribute / level } \\
\hline & \multicolumn{6}{|c|}{ US $(\mathrm{N}=103)$} & \multicolumn{6}{|c|}{ Germany $(\mathrm{N}=313)$} \\
\hline & \multicolumn{3}{|c|}{ class $1(\mathrm{~N}=57)$} & \multicolumn{3}{|c|}{ class $2(\mathrm{~N}=46)$} & \multicolumn{3}{|c|}{ class $1(\mathrm{~N}=281)$} & \multicolumn{3}{|c|}{ class $2(\mathrm{~N}=32)$} \\
\hline & $\mathrm{b}$ & & SE & $\mathrm{b}$ & & SE & $\mathrm{b}$ & & SE & $\mathrm{b}$ & & SE \\
\hline \multicolumn{13}{|l|}{ Paid leave } \\
\hline 0.5 day & -0.84 & $* * *$ & 0.14 & -0.22 & $* * *$ & 0.09 & -0.47 & $* * *$ & 0.04 & -0.15 & n.s. & 0.13 \\
\hline 1.0 day & 0.26 & $* * *$ & 0.09 & -0.05 & n.s. & 0.09 & -0.01 & n.s. & 0.03 & 0.13 & n.s. & 0.12 \\
\hline 1.5 days & 0.58 & $* * *$ & 0.12 & 0.27 & $* * *$ & 0.09 & 0.48 & $* * *$ & 0.03 & 0.02 & n.s. & 0.13 \\
\hline \multicolumn{13}{|l|}{ Money for donor } \\
\hline USD/EUR 10 & -0.98 & $* * *$ & 0.12 & -0.04 & n.s. & 0.14 & -0.34 & $* * *$ & 0.03 & -0.26 & $* * *$ & 0.13 \\
\hline USD/EUR 20 & 0.18 & $* *$ & 0.10 & -0.07 & n.s. & 0.09 & -0.06 & ** & 0.03 & 0.07 & n.s. & 0.12 \\
\hline USD/EUR 30 & 0.80 & $* * *$ & 0.12 & 0.10 & n.s. & 0.13 & 0.41 & $* * *$ & 0.04 & 0.18 & n.s. & 0.12 \\
\hline \multicolumn{13}{|l|}{ Blood screening } \\
\hline Standard & -0.65 & $* * *$ & 0.15 & 0.04 & n.s. & 0.10 & -0.51 & $* * *$ & 0.04 & -0.38 & $* * *$ & 0.12 \\
\hline Comprehensive & 0.26 & $* * *$ & 0.11 & -0.10 & n.s. & 0.09 & 0.07 & $* * *$ & 0.03 & 0.32 & $* * *$ & 0.13 \\
\hline Comprehensive plus & 0.38 & $* * *$ & 0.11 & 0.06 & n.s. & 0.09 & 0.44 & $* * *$ & 0.03 & 0.06 & n.s. & 0.13 \\
\hline \multicolumn{13}{|l|}{ Money for charity } \\
\hline USD/EUR 10 & -0.14 & n.s. & 0.11 & -0.28 & $* * *$ & 0.10 & -0.26 & $* * *$ & 0.03 & -0.07 & n.s. & 0.12 \\
\hline USD/EUR 20 & 0.03 & n.s. & 0.11 & 0.06 & n.s. & 0.09 & 0.13 & $* * *$ & 0.03 & 0.25 & $* * *$ & 0.12 \\
\hline USD/EUR 30 & 0.11 & n.s. & 0.14 & 0.23 & $* *$ & 0.12 & 0.13 & $* * *$ & 0.04 & -0.18 & n.s. & 0.13 \\
\hline \multicolumn{13}{|l|}{ Privileged receiver } \\
\hline Unknown & 0.09 & n.s. & 0.13 & -0.51 & $* * *$ & 0.12 & -0.29 & $* * *$ & 0.03 & 1.04 & $* * *$ & 0.14 \\
\hline Donor & -0.01 & n.s. & 0.10 & 0.09 & n.s. & 0.09 & -0.13 & $* * *$ & 0.04 & -0.64 & $* * *$ & 0.13 \\
\hline Immediate relative & -0.07 & n.s. & 0.12 & 0.42 & $* * *$ & 0.11 & 0.42 & $* * *$ & 0.03 & -0.40 & $* * *$ & 0.14 \\
\hline \multicolumn{13}{|l|}{ Small gift } \\
\hline Gift card & 0.10 & n.s. & 0.11 & -0.22 & $* * *$ & 0.10 & 0.03 & n.s. & 0.03 & -0.04 & n.s. & 0.14 \\
\hline Badge & 0.04 & n.s. & 0.10 & -0.18 & $* *$ & 0.09 & -0.15 & $* * *$ & 0.04 & -0.13 & n.s. & 0.13 \\
\hline Certificate & -0.15 & n.s. & 0.12 & 0.40 & $* * *$ & 0.09 & 0.12 & $* * *$ & 0.04 & 0.16 & n.s. & 0.14 \\
\hline \multicolumn{13}{|l|}{ Travel time } \\
\hline $30 \mathrm{~min}$ & -0.45 & $* * *$ & 0.12 & -0.52 & $* * *$ & 0.10 & -0.51 & $* * *$ & 0.04 & -0.73 & $* * *$ & 0.13 \\
\hline $20 \mathrm{~min}$ & -0.03 & n.s. & 0.12 & 0.03 & n.s. & 0.09 & 0.10 & $* * *$ & 0.03 & -0.12 & n.s. & 0.13 \\
\hline $10 \mathrm{~min}$ & 0.48 & $* * *$ & 0.10 & 0.49 & $* * *$ & 0.10 & 0.41 & $* * *$ & 0.04 & 0.85 & $* * *$ & 0.12 \\
\hline No-choice & -3.66 & $* * *$ & 0.43 & -2.21 & $* * *$ & 0.26 & -4.89 & $* * *$ & 0.43 & 0.21 & n.s. & 0.14 \\
\hline LL (model) & \multicolumn{6}{|c|}{-772.04} & \multicolumn{6}{|c|}{$-2,312.21$} \\
\hline AIC & \multicolumn{6}{|c|}{$1,606.08$} & \multicolumn{6}{|c|}{$4,686.42$} \\
\hline BIC & \multicolumn{6}{|c|}{$1,798.85$} & \multicolumn{6}{|c|}{$4,913.64$} \\
\hline
\end{tabular}

\section{LC Model}

For both samples, two classes were identified in the LC model (table 4). Numbers of classes mainly based on the small sample size and interpretability. A two-class solution was assumed to be most appropriate for the US sample. Respondents of class $1(\mathrm{~N}=57)$ showed a strong preference for money (Coef.: 0.80 ; $\mathrm{p}<0.01$ ) given to blood donors, paid leave (Coef.: 0.58; $\mathrm{p}<0.01$ ), blood screening test (Coef.: 0.38; $\mathrm{p}<0.01$ ), and short travel time (Coef.: 0.48; $\mathrm{p}<$ 0.01 ), which significantly affected choice decisions of respondents in this class. Choice decisions of respondents in class $2(\mathrm{~N}=46)$ were mainly affected by a short travel time (Coef.: $0.49 ; \mathrm{p}<0.01$ ), the immediate relative as privileged receiver (Coef.: $0.42 ; \mathrm{p}<0.01$ ), and a small gift (Coef.: 0.40; $\mathrm{p}<0.01$ ). Respondents seemed to be more motivated by non-economic incentives.
A two-class solution was also determined for the German sample. Respondents assigned to class $1(\mathrm{~N}=281)$ showed strong preference for paid leave (Coef.: 0.48; $\mathrm{p}<0.01$ ), blood screening test (Coef.: 0.44; $\mathrm{p}<0.01$ ), money reward (Coef.: 0.41; $\mathrm{p}<0.01$ ), immediate relative as blood receiver (Coef.: $0.42 ; \mathrm{p}<0.01$ ), and a short travel time (Coef.: 0.41; $\mathrm{p}<0.01$ ). This class seemed to be more motivated by economic incentives. Coefficient for no-option was negative (Coef.: -4.898 ; $\mathrm{p}<0.01$ ) indicating willingness to accepting one of the presented blood donation centers. Class 2 of the German sample represented the smaller subgroup $(\mathrm{N}=32)$ and consisted of respondents with an assumed moderate to strong aversion to (economic) incentives. The no-choice option turned from negative (RPL model) to positive utility in this class. Positive 


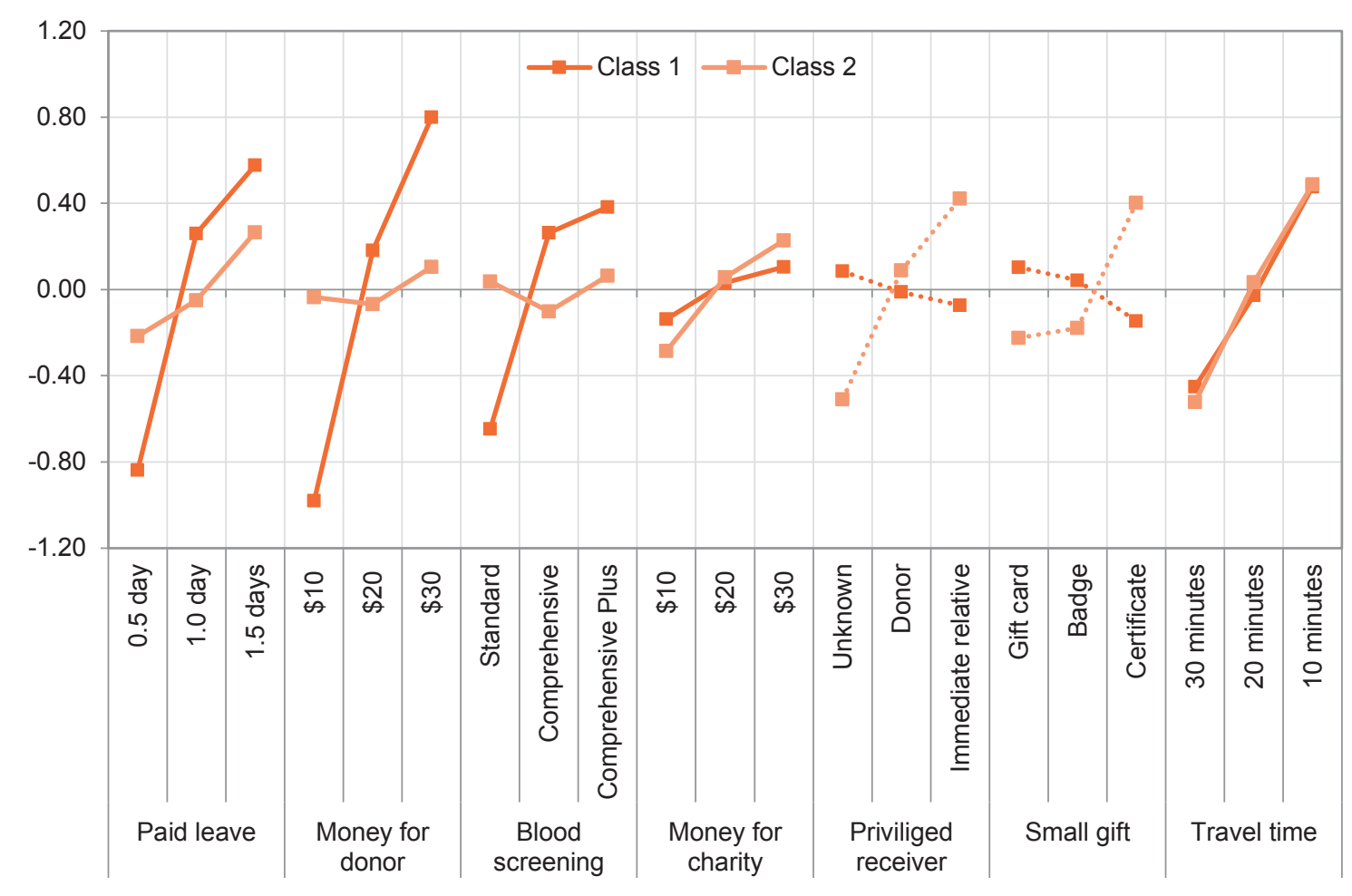

Fig. 2. $\mathrm{C}$ model and relative attribute importance (US).

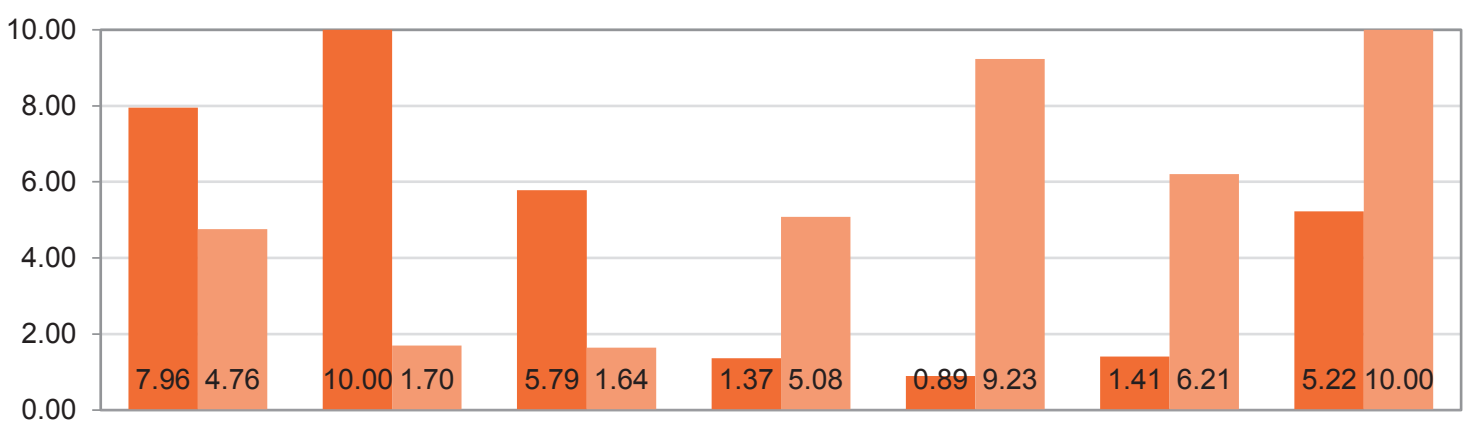

sign of the coefficient (Coef.: 0.21 ; n.s.) indicates greater utility for the no-choice option and that respondents showed a greater preference for not choosing one of the blood donation centers. The most important stimulus to choose one of the centers was the unknown privileged receiver (Coef.: 1.04; $\mathrm{p}<0.01$ ), in contrast to the immediate relative as preferred blood receiver in class 1 , and a short travel time (Coef.: $0.85 ; \mathrm{p}<0.01$ ). Remaining attributes did not seem to have a significant influence on the choice decision. Respondents in this group might be identified as donors who are probably motivated by altruistic reasons.

Figure 2 shows the graphical representation of LC model estimates and relative attribute importance of the US sample. The lower figure clearly shows the preference differences between the two classes concerning economic and non-economic stimuli. Class $1(\mathrm{~N}=57)$ opted for economic, class $2(\mathrm{~N}=46)$ for non-economic incentives.

Figure 3 represents the LC model estimates and relative attribute importance for the German sample. Similar to results of the US sample, it became apparent that the two classes within the sample distinguish from each other in terms of economic and non-economic incentives. Class $1(\mathrm{~N}=281)$ opted for economic incentives such as paid leave, blood screening test, and money. Privileged receiver of blood products in this class was an immediate relative. In contrast, the preference for the privileged receiver in class $2(\mathrm{~N}=$ 32) was the unknown individual. The donor himself was the least important level for this attribute.

Table 5 shows the characteristics of the respondents in the latent classes. Class 1 of both samples seemed to include respondents who would prefer economic incentives in exchange for blood donation. In contrast, each class 2 seemed to prefer non-economic incentives and might mainly be motivate to donate blood by altruistic reasons.

Respondents in each class 1 were younger on average than respondents in class 2 of each sample. As in the whole sample, there were more female respondents in each class of the US sample. Class 1 of the German sample has also more female respondents (56\%). In contrast, class 2 of the German sample includes more male respondents (50\%). Another difference between characteristics of the German classes concerned the status as blood donor. There were relatively more regular blood donors in class 2 (53\%). And probably therefore, more respondents in class 2 knew that they were eligible to donate blood (72\%). 


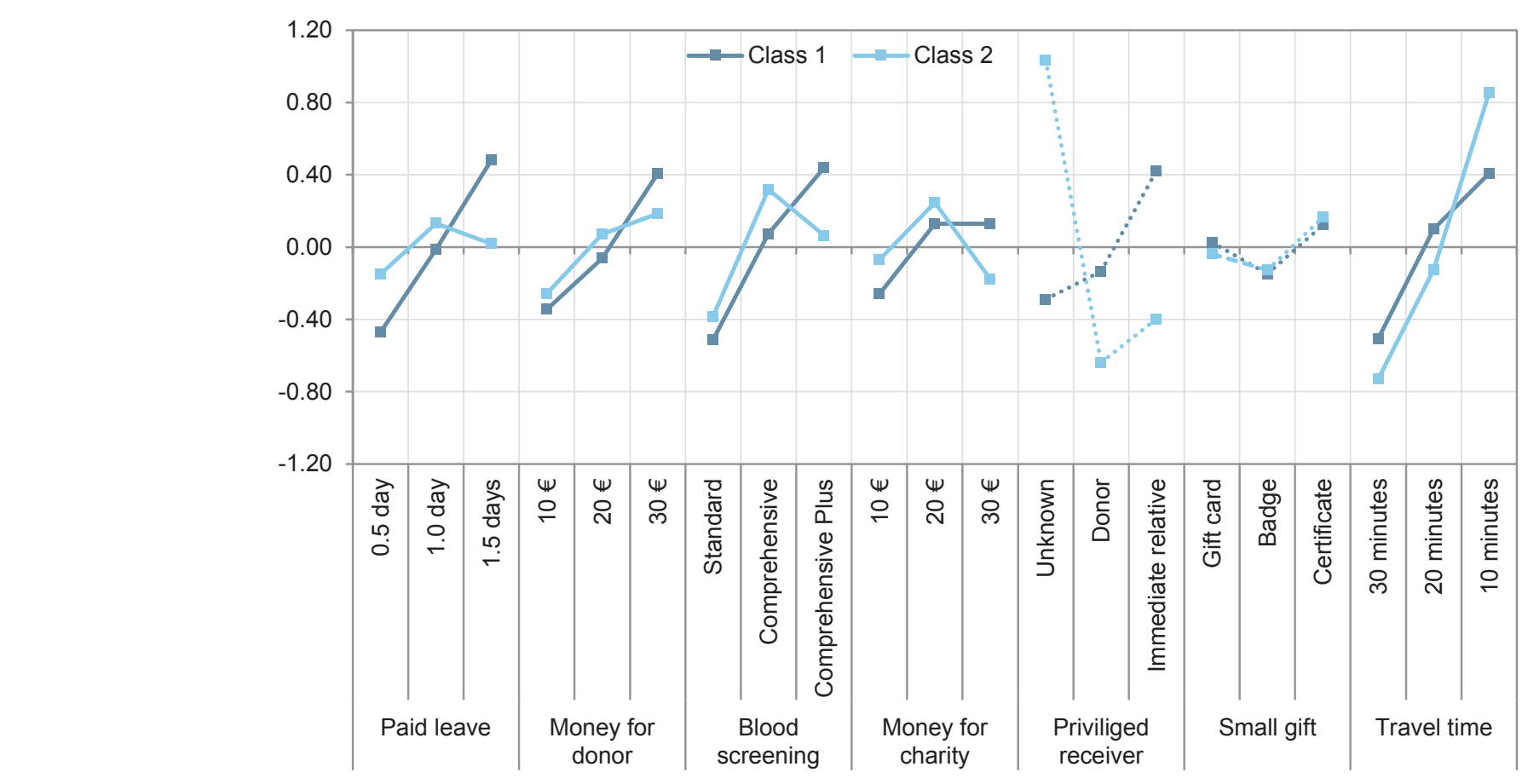

Fig. 3. LCs model and relative attribute importance (Germany).

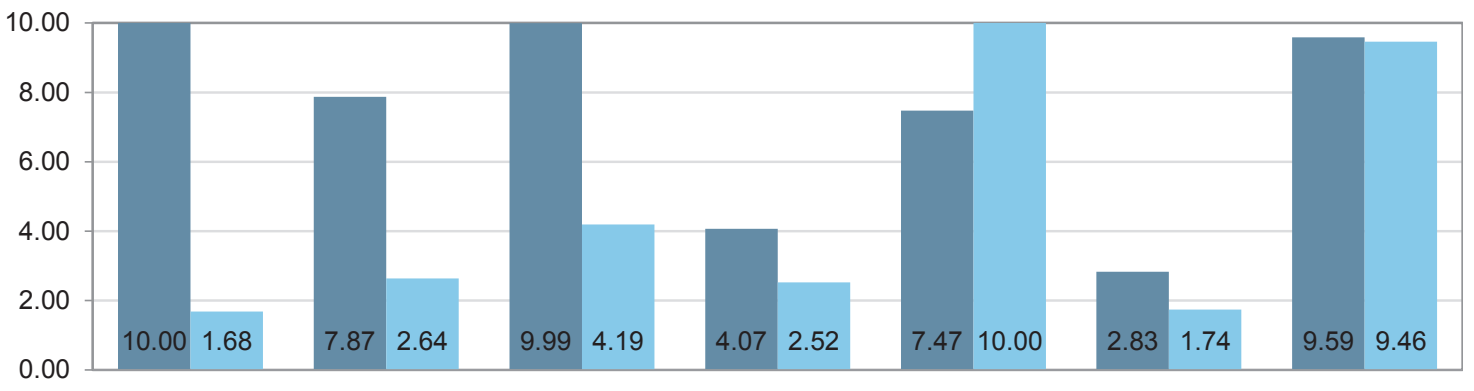

\section{Discussion}

Donor research has become an upcoming field of interest [57, 58]. To our knowledge, this is the very first time a DCE was applied to elicit preferences in the field of donor research. The study has one main finding. Donors and potential donors generally seem to be willing to accept incentives in exchange for blood donation. Researchers and authorities responsible for blood donation services should discuss a possible provision of incentives, different types of incentives, and an appropriate use of it in order to stimulate blood supply. However, the study identified distinct subgroups of individuals with different preferences for incentives. The larger class of each sample showed preferences for economic incentives such as paid leave or cash money. Respondents of the smaller groups in the samples seemed mainly to be motivated by non-economic incentives. This indicates an intention to donate blood by altruistic reasons. Economic incentives were of less interest in the smaller classes. The majority of respondents in the study showed strong preferences for incentives. This indicates that these respondents seem to be motivated to donate blood when offered incentives. This finding is conform with other studies which examined the impact of incentives for blood donation [32].

Without giving up debates on ethical issues, it might be time to reexamine policy guidelines for increasing and smoothing blood supply, including the question whether incentives might play a role [33]. But even when evidence emerges that economic rewards corrode moral value for blood donation, it remains to be determined whether this 'ethical cost' outweighs the benefits of greater supply of blood products. Existing recommendations should be reconsidered to recognize a role for incentives in generating additional safe donations [36, 37]. Current pressure caused by demographic changes and aging population indicates that the contentious issue should not only be discussed with ethical or philosophical points of view. Arguing purely with ethical arguments might inevitably lead to a practical conflict with everyday medical necessities [38]. And from a policy perspective, the need for blood calls for overcoming oppositions to incentives. It is important to find a compromise which allows for devising and implementing acceptable and successful policies to increase the blood supply [21]. Oppositions to incentives should be reconsidered, and debates on ethical issues are supposed to be encouraged. But there should be little debate that relevant empirical evidence showed positive effects of offering incentives for blood donation [33].

\section{Limitations}

The present study included university students as subjects who typically have an average age of around 25 years. The mean age of the present study participants was 25.2 (US) and 22.9 years (Germany). This limits the ability to generalize the findings to popula- 
Table 5. Respondents' characteristics in the latent classes

\begin{tabular}{|c|c|c|c|c|}
\hline & \multicolumn{2}{|l|}{ US } & \multicolumn{2}{|l|}{ Germany } \\
\hline & class $1(\mathrm{~N}=57)$ & class $2(\mathrm{~N}=46)$ & class $1(\mathrm{~N}=281)$ & class $2(\mathrm{~N}=32)$ \\
\hline Age (mean and standard deviation) & $24.9 \pm 5.4$ & $25.6 \pm 7.8$ & $22.8 \pm 2.8$ & $23.2 \pm 3.1$ \\
\hline \multicolumn{5}{|l|}{ Age groups } \\
\hline $18-20$ years & $17(30 \%)$ & $12(26 \%)$ & $67(24 \%)$ & $8(25 \%)$ \\
\hline $21-25$ years & $19(33 \%)$ & $18(39 \%)$ & $166(59 \%)$ & $18(56 \%)$ \\
\hline $26-30$ years & $11(19 \%)$ & $9(20 \%)$ & $4516 \%)$ & $516 \%)$ \\
\hline$>30$ years & $10(18 \%)$ & $7(15 \%)$ & $31 \%)$ & $13 \%)$ \\
\hline \multicolumn{5}{|l|}{ Sex } \\
\hline Female & $45(79 \%)$ & $36(78 \%)$ & $157(56 \%)$ & $14(44 \%)$ \\
\hline Male & $11(19 \%)$ & $9(20 \%)$ & $123(44 \%)$ & $16(50 \%)$ \\
\hline \multicolumn{5}{|l|}{ Household income } \\
\hline Less than USD 1,000 (EUR 750) & $16(28 \%)$ & $12(26 \%)$ & $106(38 \%)$ & $11(34 \%)$ \\
\hline USD1,000-2,000 (EUR 750-1,499) & $13(23 \%)$ & $16(35 \%)$ & $109(39 \%)$ & $14(44 \%)$ \\
\hline More than USD 2,000 (EUR 1,499) & $14(25 \%)$ & $12(26 \%)$ & $31(11 \%)$ & $7(22 \%)$ \\
\hline \multicolumn{5}{|l|}{ Status as blood donor } \\
\hline Regular donor & $15(26 \%)$ & $6(13 \%)$ & $83(29 \%)$ & $17(53 \%)$ \\
\hline Donor, but not in recent 2 years & $15(26 \%)$ & $15(32 \%)$ & $51(18 \%)$ & $6(19 \%)$ \\
\hline Never donated & $26(46 \%)$ & $23(50 \%)$ & $142(51 \%)$ & $9(28 \%)$ \\
\hline \multicolumn{5}{|l|}{ Eligible to donate } \\
\hline Yes & $25(44 \%)$ & $25(54 \%)$ & $134(48 \%)$ & $23(72 \%)$ \\
\hline No & $13(23 \%)$ & $7(15 \%)$ & $59(21 \%)$ & $2(6 \%)$ \\
\hline Don’t know & $1933 \%)$ & $12(26 \%)$ & $86(31 \%)$ & $6(19 \%)$ \\
\hline
\end{tabular}

tions beyond students. The study results do not reflect how nonstudents and older people would respond to offered incentives.

Characteristics such as sex, income, or education do not seem to affect the probability of being a blood donor [59]. No easily identifiable characteristics could readily predict donation behavior, and demographic characteristics alone were insufficient to predict willingness to donate blood [60] as the decision to donate blood is a complex mix of individual and social determinants including willingness to help others, desire for recognition and self-esteem, and appropriate rewards [61]. No previous research showed clear evidence that demographic characteristics were causally related to willingness to donate. However, prior studies examined the influence of sociodemographic factors on the willingness to donate and gave directions for the recruitment of blood donors [62, 63]. Knowledge about demographic information could provide blood centers with a way to monitor trends of current donors, identify potential populations, and help adjusting donor recruitment and retention strategies [64]. Characteristics might be expected to affect preferences but were not particularly taken into account in regression models in this study. Therefore, estimating the role of sociodemographic characteristics in explaining (latent) class membership probabilities would be a valuable feature in future research.

Due to the small sample, the most interpretable solution for the LC models was chosen without referring to statistical model fit criteria. An empirical approach typically would be to examine LC models with more than two classes and look for the most interpretable solution and/or the solution with the best model fit.
Another limitation refers to the hypothetical blood donation centers in the study. It is not very realistic to reward blood donors with various economic incentives at the same time such as money, paid leave, and a comprehensive, probably costly blood screening test.

\section{Conclusion}

The goal of this study was to provide information to the discussion on how to increase blood donation rates and to answer the question whether citizens were willing to accept incentives in exchange for blood donation. From a policy perspective, the study results allow to conclude that the provision of incentives may motivate citizens to donate blood and to increase blood donation rates (while ignoring potential cost factors). A major part of respondents positively responded to incentives. In conclusion, the study found that individuals are willing to accept incentives for blood donation. Accepting incentives, therefore, might not necessarily interfere with the idea of blood donation as a good deed and an act of solidarity. Appropriately utilized incentives might also help overcome fear and laziness as most commonly reported obstacles to donating blood [30]. This study highlights that the judicious use of incentives might be an option to motivate potential donors and should at least be open to discussion.

\section{Disclosure Statement}

Andrew Sadler received a funding from IALS (International Academy of Life Sciences). 


\section{References}

1 Currie C, Patel T, McEwan P, Dixon S: Evaluation of the future supply and demand for blood products in the United Kingdom National Health Service. Transfus Med 2004;14:19-24.

2 Ehling M, Pötzsch O: Demographic changes in Germany up to 2060 - consequences for blood donation. Transfus Med Hemother 2010;37:131-139.

3 Katalinic A, Peters E, Beske F, Pritzkuleit R: Projection of morbidity 2030 and 2050:impact for the national health system and blood supply. Transfus Med Hemother 2010;37:155-159.

4 Greinacher A, Fendrich K, Brzenska R, Kiefel V, Hoffmann W: Implications of demographics on future blood supply: a population-based cross-sectional study. Transfusion 2011;51:702-709.

5 Ritter S, Hamouda O, Offergeld R: Demografie und Spendeaktivität von Blut-und Plasmaspendern in Deutschland. Bundesgesundheitsbl Gesundheitsforsch Gesundheitsschutz 2012;55:914-922.

6 Schiefer G: Motive des Blutspendens: tiefenpsychologische Untersuchung mit Gestaltungsoptionen für das Marketing von Nonprofit-Organisationen des Blutspendewesens. Heidelberg, Springer, 2006.

7 Boenigk S, Leipnitz S, Scherhag C: Altruistic values, satisfaction and loyalty among first-time blood donors. International Journal of Nonprofit and Voluntary Sector Marketing 2011:16:356-370.

8 Borkent-Raven BA, Janssen MP, Van Der Poel CL: Demographic changes and predicting blood supply and demand in the Netherlands. Transfusion 2010;50 2455-2460.

9 Lacetera N, Macis M: Social image concerns and prosocial behavior: Field evidence from a nonlinear incentive scheme. J Econ Behav Organization 2010;76: 225-237.

10 Lemmens KPH: The Systematic Recruitment of New Blood Donors. Maastricht University, dotoral thesis, 2009

11 Department of Health and Human Services: The 2011 National Blood Collection and Utilization Survey Report. Washington, DC, Department of Health and Human Services, 2013.

12 Henseler O, Heiden M, Haschberger B, Hesse J, Seitz R: Bericht zur Meldung nach $\$ 21$ TFG für die Jahre 2010 und 2011. BundesgesundheitsblGesundheitsforsch Gesundheitsschutz 2013;56:1352-1367.

13 Lacetera N, Macis M: Motivating altruism: a field study. IZA Discussion Paper 2008:3770. https://papers. ssrn.com/sol3/papers.cfm?abstract_id $=1290039$ (last accessed December 28, 2017).

14 Goette L, Stutzer A, Yavuzcan G, Frey BM: Free cholesterol testing as a motivation device in blood donations: evidence from field experiments. Transfusion 2009;49:524-531.

15 Farrugia A, Penrod J, Bult J: Payment, compensation and replacement-the ethics and motivation of blood and plasma donation. Vox Sang 2010;99:202-211.

16 Lacetera N, Macis M: Time for blood: the effect of paid leave legislation on altruistic behavior. Journal of Law, Economics, and Organization 2012: doi:10.1093/jleo/ ews019.

17 World Health Organization: The Melbourne Declaration on $100 \%$ Voluntary Non-Remunerated Donation of Blood and Blood Components, 2009. Geneva, World Health Organization, 2009.

18 World Health Organization: Towards 100\% Voluntary Blood Donation: A Global Framework for Action. Geneva, World Health Organization, 2010.

19 Gneezy U, Meier S, Rey-Biel P: When and why incentives (don't) work to modify behavior. J Econ Perspect 2011;25:191-209.

20 Van der Poel C, Seifried E, Schaasberg W: Paying for blood donations: still a risk? Vox Sang 2002;83:285-293.
21 Buyx AM: Blood donation, payment, and non-cash incentives: classical questions drawing renewed interest. Transfus Med Hemother 2009;36:329-339.

22 Lacetera N, Macis M: Do all material incentives for prosocial activities backfire? the response to cash and non-cash incentives for blood donations. J Econ Psychol 2010;31:738-748.

23 Glynn S., Williams AE, Nass CC, Bethel J, Kessler D,Scott EP, Fridey J, Kleinman SH, Schreiber GB: Attitudes toward blood donation incentives in the United States: implications for donor recruitment. Transfusion 2003;43:7-16.

24 Costa-Font J, Jofre-Bonet M, Yen ST: Not all incentives wash out the warm glow: the case of blood donation revisited. Kyklos 2013;66:529-551.

25 Marantidou O, Loukopoulou L, Zervou E, Martinis G, Egglezou A, Fountouli P, Dimoxenous P, Parara M, Gavalaki M, Maniatis A: Factors that motivate and hinder blood donation in Greece. Transfus Med 2007; 17:443-450.

26 del Pozo PR: Paying donors and the ethics of blood supply. J Med Ethics 1994;20:31-35.

27 Mellström C, Johannesson M: Crowding out in blood donation: was Titmuss right? J Eur Econo Assoc 2008; 6:845-863.

28 Steele WR, Schreiber GB, Guiltinan A, Nass C, Glynn SA, Wright DJ, Kessler D, Schlumpf KS, Tu Y, Smith JW: The role of altruistic behavior, empathetic concern, and social responsibility motivation in blood donation behavior. Transfusion 2008;48:43-54.

29 Ringwald J, Lange N, Rabe C, Zimmermann R, Strasser E, Hendelmeier M, Strobel J, Eckstein R: Why do some apheresis donors donate blood just once? Vox Sang 2007;93:354-362.

30 Sojka BN, Sojka P: The blood donation experience: self-reported motives and obstacles for donating blood. Vox Sang 2008;94:56-63.

31 Bednall TC, Bove LL: Donating blood: a meta-analytic review of self-reported motivators and deterrents. Transfus Med Rev 2011;25:317-334.

32 Lacetera N, Macis M, Slonim R: Will there be blood? Incentives and substitution effects in pro-social behavior. 2009, IZA Discussion Paper 2009:4567 https:// papers.ssrn.com/sol3/papers.cfm?abstract_id $=1515114$ (last accessed December 28, 2017).

33 Lacetera N, Macis M, Slonim R: Economic rewards to motivate blood donations. Science 2013;340:927-928.

34 Dhingra N: In defense of WHO's blood donation policy. Science 2013;342:691-692.

35 Berger M: The Value of incentives in blood donation. Scienc 2013;341:128-129.

36 Lacetera N, Macis M, Slonim R: Response to Berger's The Value of Incentives in Blood Donation. Science 2013;341:129.

37 Lacetera N, Macis M, Slonim R: Response to Dhingra's In Defense of WHO's Blood Donation Policy. Science 2013;342:692.

38 von Auer F: Das neue Transfusionsgesetz. Eine Darstellung der wesentlichen Aspekte. Bundesgesundheitsbl Gesundheitsforsch Gesundheitsschutz 1999;42:95-99.

39 Bridges JF, Mohamed AF, Finnern HW, Woehl A, Hauber AB: Patients' preferences for treatment outcomes for advanced non-small cell lung cancer: A conjoint analysis. Lung Cancer 2012;77:224-231.

40 de Bekker-Grob EW, Ryan M, Gerard K: Discrete choice experiments in health economics: a review of the literature. Health Econ 2012;21:145-172.

41 Mühlbacher A, Bethge S, Tockhorn A: Präferenzmessung im Gesundheitswesen: Grundlagen von DiscreteChoice-Experimenten. Gesundheitsökonomie Qualitätsmanagement 2013;18:159-172.

42 Muhlbacher A, Stoll M, Mahlich J, Nubling M: Patient preferences for HIV/AIDS therapy - a discrete choice experiment. Health Econ Rev 2013;3:14.
43 Ryan M, Gerard K, Amaya-Amaya M (eds): Using Discrete Choice Experiments to Value Health and Health Care. Heidelberg, Springer, 2008

44 Bliemer MC, Rose JM: Experimental design influences on stated choice outputs: an empirical study in air travel choice. Transportation Research Part A: Policy and Practice 2011;45:63-79.

45 Hensher DA, Rose JM, Greene WH: Applied Choice Analysis: A Primer. Cambridge, Cambridge University Press, 2005.

46 Bridges JF, Hauber AB, Marshall D, Lloyd A, Prosser LA, Regier DA, Johnson FR, Mauskopf J: Conjoint analysis applications in health - a checklist: a report of the ISPOR Good Research Practices for Conjoint Analysis Task Force. Value Health 2011;14:403-413.

47 ChoiceMetrics: Ngene 1.1. 1 User Manual \& Reference Guide. Sydney, ChoiceMetrics, 2012.

48 Bech M, Gyrd-Hansen D: Effects coding in discrete choice experiments. Health Econ 2005;14:1079-1083.

49 Hole AR: Estimating mixed logit models using maximum simulated likelihood. Stata J 2007;7(3:388-401.

50 Pacifico D, Yoo HI: lclogit: a Stata module for estimating latent class conditional logit models via the Expectation-Maximization algorithm. 2012. https://ideas. repec.org/p/swe/wpaper/2012-49.html (last accessed December 28, 2017).

51 Hiligsmann M, Dellaert BG, Dirksen CD, van der Weijden T, Goemaere S, Reginster J-Y, Watson V, Boonen A: Patients' preferences for osteoporosis drug treatment: a discrete-choice experiment. Arthritis Res Ther 2014;16:R36.

52 Train KE: Discrete Choice Methods with Simulation. Cambridge, Cambridge University Press, 2009.

53 Orme BK: Getting Started with Conjoint Analysis. Strategies for Product Design and Pricing Research 2nd ed. Chicago, Research Publishers LLC, 2010.

54 Mohamed AF, Johnson FR, Balp M-M, Calado F: Preferences and stated adherence for antibiotic treatment of cystic fibrosis pseudomonas infections. Patient 2016;9:59-67.

55 Mühlbacher AC, Bethge S: Patients' preferences: a discrete-choice experiment for treatment of non-smallcell lung cancer. Eur J Health Econ 2015; 16:657-670.

56 Hauber AB, Mohamed AF, Johnson FR, Meddis D, Wagner S, O’Dowd L: Quantifying asthma patient preferences for onset of effect of combination inhaled corticosteroids and long-acting beta2-agonist maintenance medications. Allergy Asthma Proc 2009;30:139-147.

57 Müller-Steinhardt M, Bugert P: Donor research-an upcoming field of interest all over the world! Transfus Med Hemother 2014;41:240-241.

58 Shi L, Wang J, Liu Z, Stevens L, Sadler A, Ness P, Shan $\mathrm{H}$ : Blood donor management in China. Transfus Med Hemother 2014;41:273-282.

59 Priller E, Schupp J: Soziale und ökonomische Merkmale von Geld-und Blutspendern in Deutschland. Wochenbericht 2008;78:3-10.

60 Holdershaw J, Gendall P, Wright M: Factors influencing blood donation behaviour. ANZMAC 2007, Conference Paper, 2007.

61 Riedel S, Hinz A, Schwarz R: Einstellung zur Blutspende in Deutschland - Ergebnisse einer repräsentativen Untersuchung. Transfus Med Hemother 2000;27:196-199.

62 Tscheulin DK, Lindenmeier J: The willingness to donate blood: an empirical analysis of socio-demographic and motivation-related determinants. Health Services Manage Res 2005;18(3:165-174.

63 Misje AH, Bosnes V, Gåsdal O, Heier HE: Motivation, recruitment and retention of voluntary non-remunerated blood donors: a survey-based questionnaire study. Vox Sang 2005;89:236-244.

64 Wu Y, Glynn SA, Schreiber GB, Wright DJ, Lo A,Murphy EL, Kleinman SH, Garratty G: First-time blood donors: demographic trends. Transfusion 2001;41:360-364. 